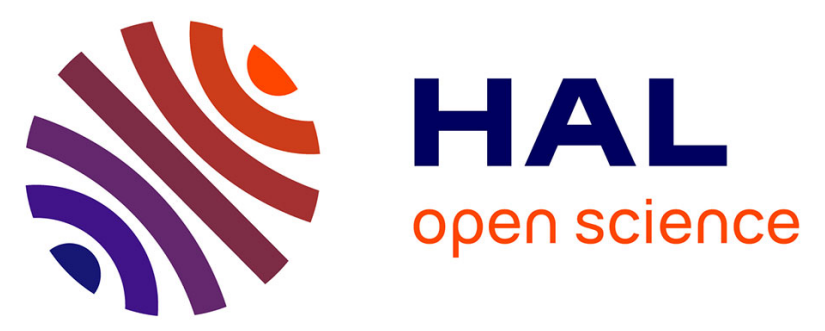

\title{
Preparation of YBCO on YSZ Layers Deposited on Silicon and Sapphire by MOCVD : Influence of the Intermediate Layer on the Quality of the Superconducting Film
}

G. Garcia, J. Casado, J. Llibre, M. Doudkowski, J. Santiso, A. Figueras, Sylvie Schamm-Chardon, Dominique Dorignac, Ch. Grigis, M. Aguilò

\section{To cite this version:}

G. Garcia, J. Casado, J. Llibre, M. Doudkowski, J. Santiso, et al.. Preparation of YBCO on YSZ Layers Deposited on Silicon and Sapphire by MOCVD: Influence of the Intermediate Layer on the Quality of the Superconducting Film. Journal de Physique IV Proceedings, 1995, 05 (C5), pp.C5-439C5-447. 10.1051/jphyscol:1995551 . jpa-00253913

\section{HAL Id: jpa-00253913 https://hal.science/jpa-00253913}

Submitted on 1 Jan 1995

HAL is a multi-disciplinary open access archive for the deposit and dissemination of scientific research documents, whether they are published or not. The documents may come from teaching and research institutions in France or abroad, or from public or private research centers.
L'archive ouverte pluridisciplinaire HAL, est destinée au dépôt et à la diffusion de documents scientifiques de niveau recherche, publiés ou non, émanant des établissements d'enseignement et de recherche français ou étrangers, des laboratoires publics ou privés. 


\title{
Preparation of YBCO on YSZ Layers Deposited on Silicon and Sapphire by MOCVD: Influence of the Intermediate Layer on the Quality of the Superconducting Film
}

\author{
G. Garcia, J. Casado, J. Llibre, M. Doudkowski*, J. Santiso*, A. Figueras*, S. Schamm**, \\ D. Dorignac**, Ch. Grigis** and M. Aguilò***
}

S.E. Carburos Metàlicos, $P^{\circ}$ Zona Franca 14-20, 08038 Barcelona, Spain

* ICMAB/CSIC, Campus U.A.B., 08193 Bellaterra, Spain

** CEMES-LOE/CNRS, 29 rue Jeanne Marvig, BP. 4347, 31055 Toulouse, France

*** Universitat Rovira i Virgili, Pl Imperial Tarraco, 43000 Tarragona, Spain

\begin{abstract}
YSZ buffer layers were deposited on silicon and sapphire by MOCVD. The layers deposited on silicon were highly oriented along [100] direction without in-plane orientation, probably because the existence of the $\mathrm{SiO}_{2}$ amorphous interlayer. In contrast, epitaxial YSZ was obtained on (1-102) sapphire showing an inplane texture defined by the following relationships: (100) YSZ // (1-102) sapphire and (110) YSZ // (01-12) sapphire. Subsequently, YBCO films were deposited on YSZ by MOCVD. Structural, morphological and electrical characterization of the superconducting layers were correlated with the in-plane texture of the buffer tayers.
\end{abstract}

\section{INTRODUCTION}

High quality $\mathrm{YBa}_{2} \mathrm{Cu}_{3} \mathrm{O}_{7 . \delta}(\mathrm{YBCO}$ ) thin films with high critical current densities should be deposited on substrates such as silicon and sapphire for the integration of superconductors in microelectronics and microwave applications. It is well known that YBCO reacts chemically with silicon [1] and sapphire [2] at temperatures above $600^{\circ} \mathrm{C}$, leading to a strong deterioration of the superconducting properties of the films. Therefore, a suitable buffer layer acting as a diffusion barrier should be deposited on these substrates for the preparation of epitaxial YBCO layers. Yttria-Stabilized Zirconia (YSZ) fulfils the properties required to this interlayer [3].

High-quality $\mathrm{YBCO}$ superconducting thin films ( $\mathrm{Tc}=89 \mathrm{~K}$ and critical current densities $J_{c}=10^{6} \mathrm{~A} / \mathrm{cm}^{2}$ ) have been prepared on YSZ buffer layers deposited on sapphire [4] and silicon [5] by PVD techniques. It should be noted that, MOCVD technique has also been used for the deposition of YBCO/YSZ/sapphire[6,7] and YBCO/YSZ/Si [8] multilayers, but high critical current densities have only been obtained on sapphire substrates[9].

In this paper we present results of a morphological, structural and electrical characterization of YBCO films and YSZ buffer layers deposited on silicon and sapphire by MOCVD.

\section{EXPERIMENTAL}

\subsection{YSZ film deposition by MOCVD}

YSZ films were deposited on silicon (100) and sapphire (1-102) in a quartz hot wall reactor. $\mathrm{Zr}$ and $\mathrm{Y}$ complexes of $2,2,4,4$ - tetramethyl-3,5, heptanedione $\left(\mathrm{Zr}(\text { thd })_{4}\right.$ and $\left.\mathrm{Y}(\mathrm{thd})_{3}\right)$ were used as precursors. The evaporation temperatures were ranged between $123-125^{\circ} \mathrm{C}$ and $145-150^{\circ} \mathrm{C}$ for yttrium and zirconium precursors, respectively. The argon carrier flow was $150 \mathrm{sccm}$ for every source and an oxygen flow of $300 \mathrm{sccm}$ was added downstream in a mixing zone. Typical substrate temperature range was $680-750^{\circ} \mathrm{C}$ for Y'ST on Si deposition (YSZ/Si) and $820-860^{\circ} \mathrm{C}$ for Y Y $\mathrm{SZ}$ on 
sapphire deposition (YSZ/sapphire). No attempt was made to remove the native oxide layer from silicon (100).

The total pressure in the reactor was held at 5 torr. The thickness in both cases was evaluated in $300 \mathrm{~nm}$ by ellipsometry.

\subsection{YBCO deposition by MOCVD}

YBCO layers were also obtained by thermal activated MOCVD. Argon was used as a carrier gas and oxygen was also added to the main flow. The source materials were $\mathrm{Y}$ (thd $)_{3}, \mathrm{Ba}$ (thd) 2 and $\mathrm{Cu}$ (thd) . $_{2}$. Typical source temperatures were $117.5,103.4,212^{\circ} \mathrm{C}$ for $\mathrm{Y}, \mathrm{Ba}$ and $\mathrm{Cu}$ precursor respectively with an individual carrier gas flow of $50 \mathrm{sccm}$. The oxygen flow was $150 \mathrm{sccm}$. The total pressure in the reactor was kept at 10 torr. The deposition temperature of YBCO on YSZ buffer layer was ranged between 845 and $910^{\circ} \mathrm{C}$.

\section{RESULTS AND DISCUSSION}

\subsection{YSZ buffer layers preparation}

\subsection{Siructure}

XRD analysis performed on both types of YSZ buffer layers demonstrate that films were highly oriented along [100] direction.

Figure. la depicts the diffractogram obtained on YSZ/Si. Samples showed a (200) preferential reflection corresponding to the cubic YSZ structure. The FWHM of the rocking curve performed on this reflection was $10^{\circ}$.

In contrast, the FWHM of the rocking curve carried out on the (200) reflection of YSZ deposited on sapphire (1-102) (figure.1b) was close to $1^{\circ}$, indicating the highly oriented nature of the films.
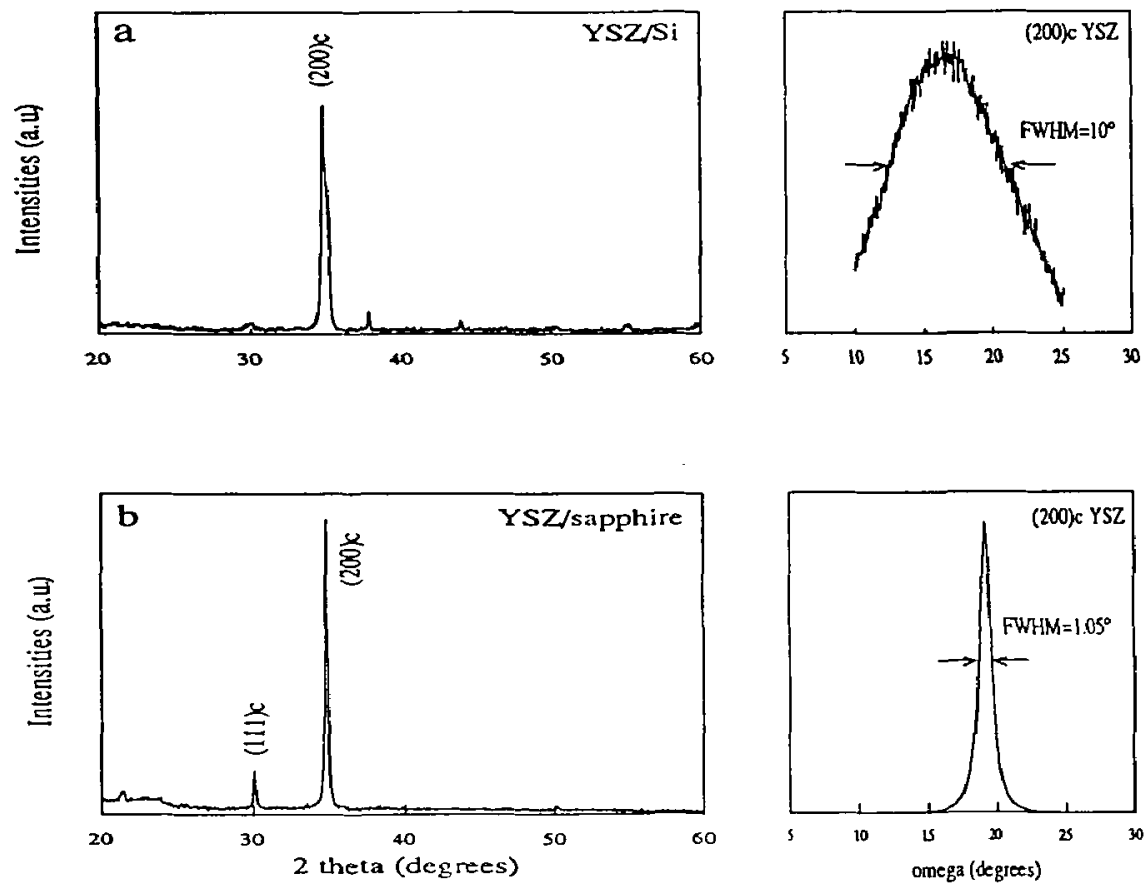

Figure.1: XRD patem of YSZ deposited on (a) silicon at $750^{\circ} \mathrm{C}$ and (b) on sapphire (1-102) at $820^{\circ} \mathrm{C}$. Rocking scans trough (200) reflection of YSZ film deposited on silicon and on sipphire are also shown. 
The in-plane texture and the epitaxial relationships between films and substrates were studied by means of the pole figures corresponding to the (202) and (222) film reflections and the (300) and (006)-sapphire and (202)-silicon substrates reflections.

The pole figure of (202) reflection of YSZ films deposited on silicon shows a continous ring shape without local maxima indicating that there exits no in-plane orientation and consequently there is no predominant alignment between layer and substrate. This fact was already suggested by the FHWM results.

Figure. 2 shows the 3-dimensional pole figure corresponding to the (202)-YSZ reflection deposited on sapphire. The presence of four peaks separated by $\phi=90^{\circ}$ at $\psi=45^{\circ}$ confirms the inplane texture of the films. A combined pole figure of the (202) and (222) film reflections and the substrate (006)S and (300)S reflection, is shown in fig.2.
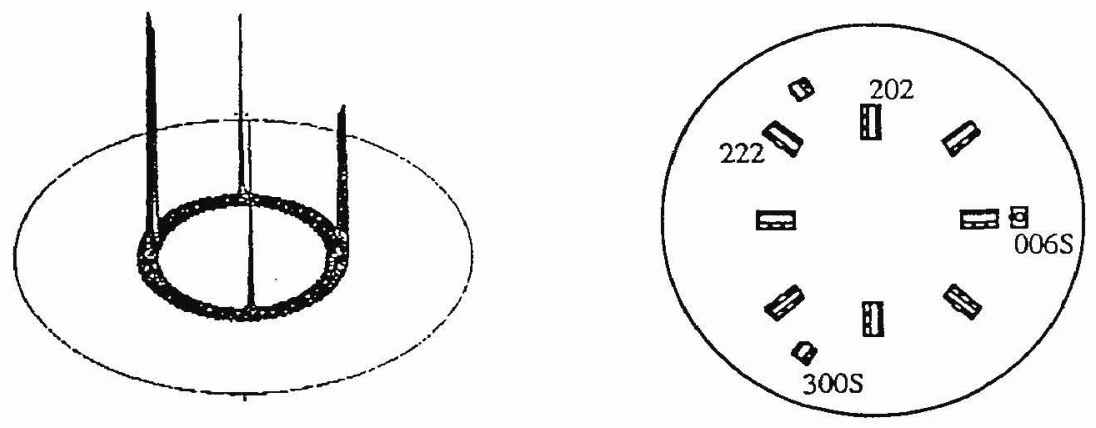

figure.2: (202)-YSZ reflection pole figure (on the left). A combined (202) and (222)-YSZ reflections and (006) and (300)- sapphire reflection pole figures (on the right side).

The epitaxial relationships between layer and substrate can be obtained from this figure and described as:

(100)YSZ // (1-102) sapphire and (110) YSZ // (01-12) sapphire

\subsubsection{Morphology and microstructure}

Figure.3a shows the scanning electron micrograph of a tilted surface and cross-section of YSZ layer deposited on silicon. The surface of the films was slightly rough with a high density of grain boundaries. The films exhibit columnar growth. Microstructural analysis was performed by TEM.

Figure.3b shows a $30 \mathrm{~nm}$ thick $\mathrm{SiO}_{2}$ interlayer observed between $\mathrm{YSZ}$ and $\mathrm{Si}$ for a layer deposited at $750^{\circ} \mathrm{C}$.
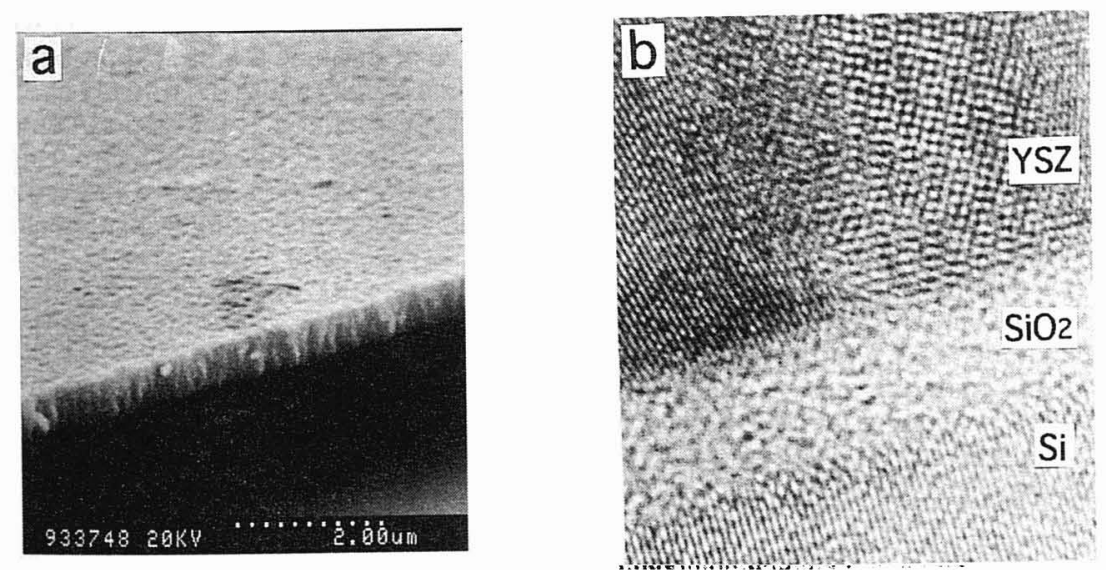

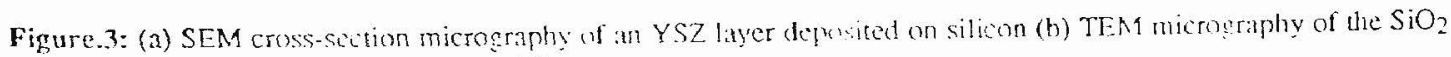
interlayer observed berween silfeon and YSZ. 
Microstructural analysis performed on YSZ deposited at $820^{\circ} \mathrm{C}$ on sapphire showed that buffer layers follow a two dimensional growth up to a thickness close to $100 \mathrm{~nm}$ [10]. Above this value, the growth becomes columnar with cristalline domains oriented along the [100] direction as shown in figure 4.

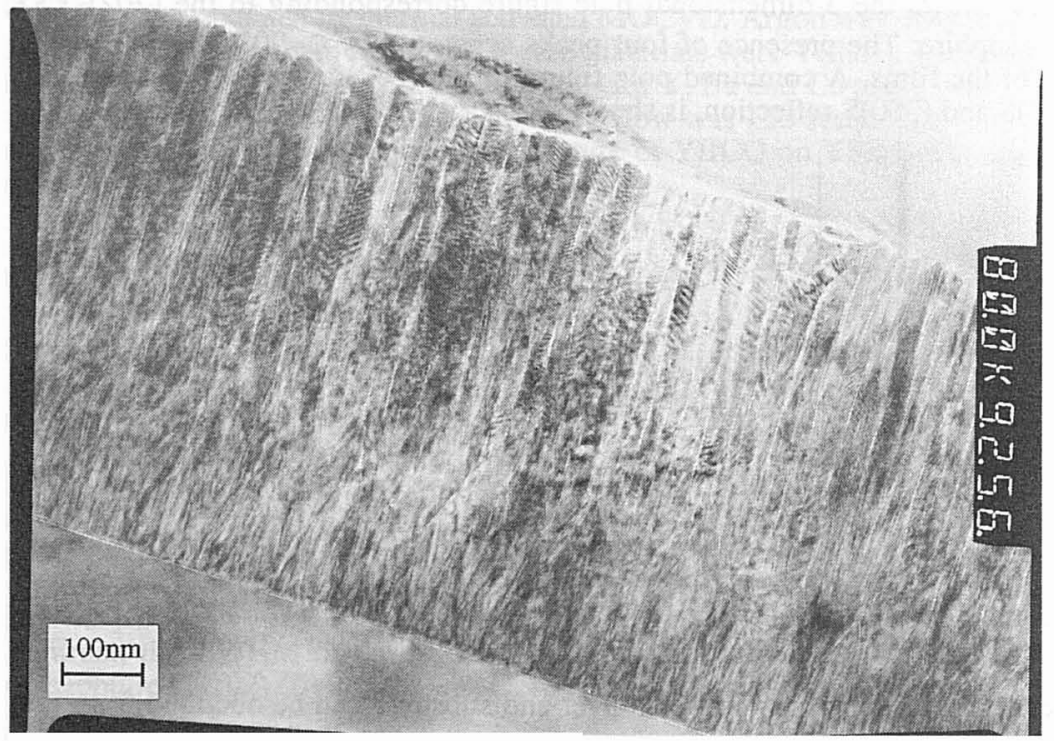

Figure.4: TEM micrography of a YSZ buffer layer obtained on sapphire at $820^{\circ} \mathrm{C}$.

\subsection{YBCO layers}

\subsubsection{YBCO/YSZ/Si}

YSZ films deposited on silicon (100) substrates covered by native oxide were highly (100)-oriented, but polycristalline. The YBCO films deposited on these buffer layers by MOCVD were highly coriented but also polycristalline showing a certain degree of in-plane texture [8] probably induced by the formation of a non uniform $\mathrm{BaZ}_{\mathrm{rO}_{3}}$ interlayer between YBCO and YSZ films [11].

Figure.5 displays the morphology of YBCO layer obtained at the experimental conditions described before. At high temperature $\left(910^{\circ} \mathrm{C}\right)$, the layers consist of disconnected rectangular crystals coexisting with well developed sticks. At lower temperature $\left(845^{\circ} \mathrm{C}\right)$, the layers become continous with connected crystals but the material does not exhibit a superconducting transition at temperatures above $77 \mathrm{~K}$.

Our results confirm the lack of experimentals results on YBCO/YSZ/Si deposited by MOCVD. Up to now, only Electron Beam Evaporation [12] and Laser Ablation [13] are known to result in epitaxial YSZ films on silicon.

In any case, the quality of the YBCO layers deposited on YSZ/Si by MOCVD should be improved by eliminating the $\mathrm{SiO}_{2}$ interlayer in order to reduce the misorientation along c-axis and/or spreading an uniform $\mathrm{BaZ}_{\mathrm{rO}}$ interlayer on the YSZ surface in order to enhance the two dimentional growth of the YBCO films. 


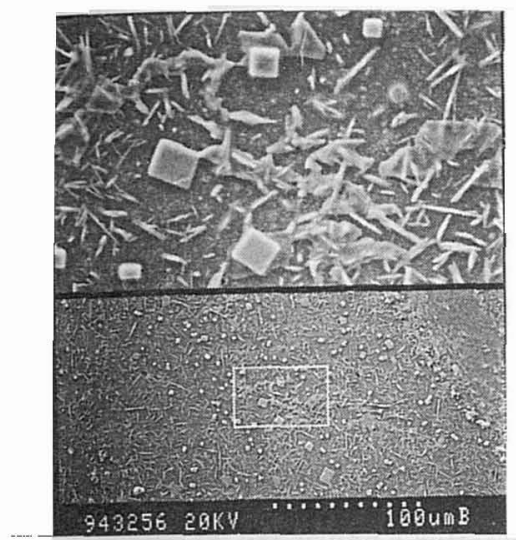

a

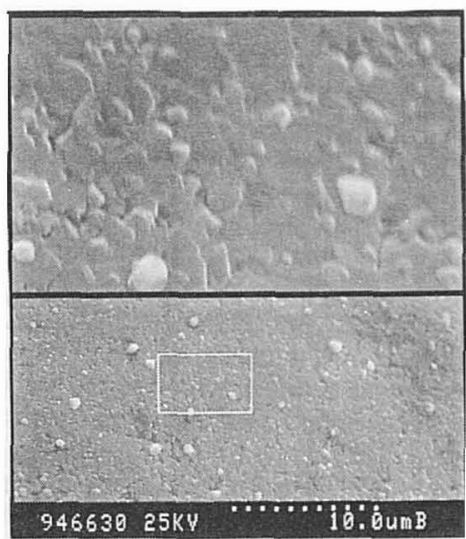

b

Figure.5: SEM micrograph of the surface of an YBCO layer grown on YSZ/Si by MOCVD at (a) $910^{\circ} \mathrm{C}$ and (b) $845^{\circ} \mathrm{C}$.

\subsubsection{YBCO/YSZ/Sapphire}

YBCO films were deposited at $800^{\circ} \mathrm{C}$ on sapphire coated with an epitaxial YSZ buffer layer. The XRD pattern of YBCO film (figure.6) shows that the layers were highly c-orientated. The FWHM of the $(005)$ reflection rocking curve was evaluated in $1.35^{\circ}$.
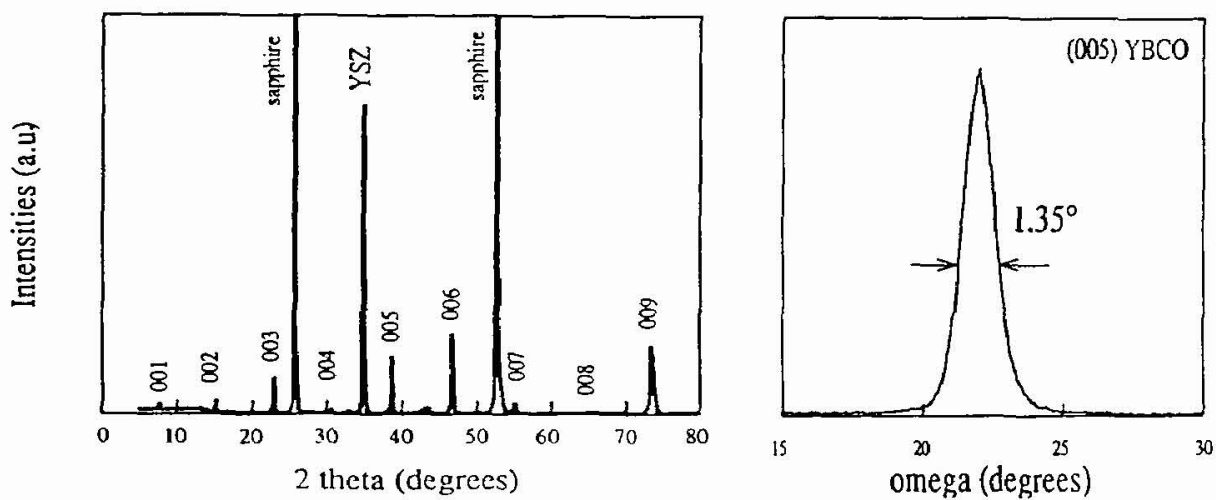

Figure.6: XRD pattem of YBCO deposited on sapphire with an (100) epitaxial YSZ buffer layer. Figure on the right shows the rocking scan across the (005) YBCO reflection.

The in-plane texture was assessed by mapping the (103)-YBCO reflection phi-scan. As it is shown in figure.7, the comparison between (103)-YBCO and (111)-YSZ reflections phi-scans prove that YBCO lattice is $45^{\circ}$ rotated with respect to the YSZ one. The epitaxial relationships can be described as :

$[001] \mathrm{YBCO} / /[100] \mathrm{YSZ}$ and [100], [010] YBCO // [110] YSZ. 


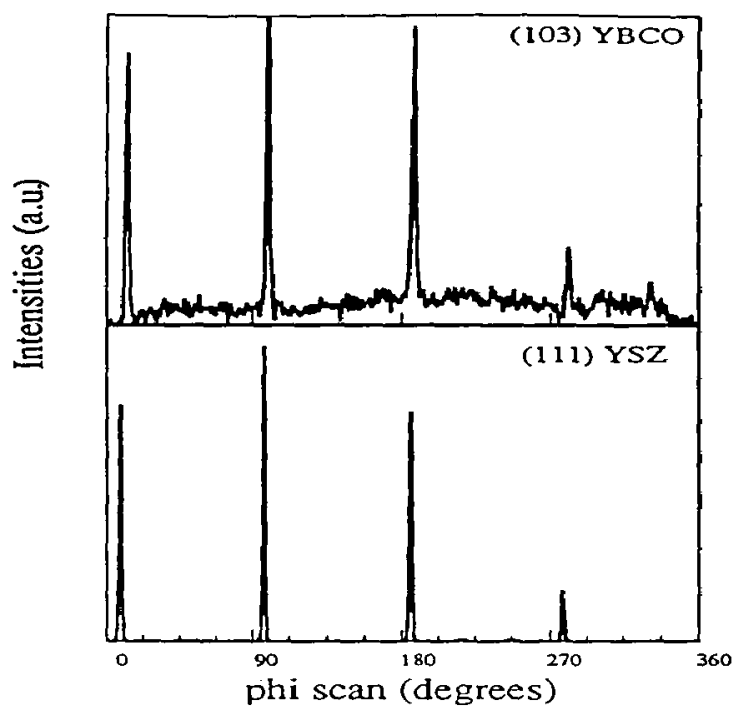

Figure.7: phi-scan patterns of (103)-YBCO and (111)-YSZ reflections.

The YBCO layers show a continous morphology with a slight roughness. In this case, the films fulfil the suitable experimental conditions [see 3.2.1] for the growth of high quality YBCO layer on YSZ: a) small misorientation between crystallites, in spite of its small size b) uniform $\mathrm{BaZrO}_{3}$ interlayer wich probably exists due to the high deposition temperature [11].

The critical temperature was evaluated by means of an AC-susceptometer. Figure. 8 shows the real and imaginary parts of the A C-susceptibility measured at $0.1 \mathrm{Oe}$, indicating a $\mathrm{T}_{\mathrm{C}}$ (onset) above $88 \mathrm{~K}$ for a $120 \mathrm{~nm}$-thick YBCO layer on YSZ/sapphire. Critical current density was evaluated in $\mathrm{J}_{\mathrm{C}}=1.5 .10^{5} \mathrm{~A} / \mathrm{cm}^{2}$ at $77 \mathrm{~K}$ by using the Bean model.

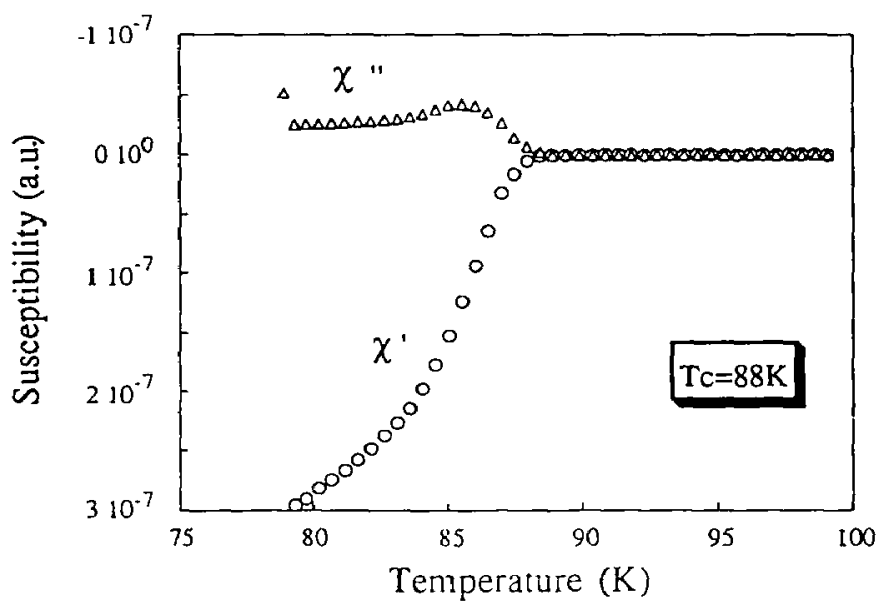

Figure.8: A C-susceptibility curve vs tomperature for a mullilayer YBCO/YSZ/sapphise. $\chi^{\prime}$ and $\chi^{\prime \prime}$ are the real and inaginary parts of the AC-susceptibility. 


\section{Conclusions}

1 - [100]-oriented YSZ buffer layers were grown on silicon (100) and sapphire (1-102) by MOCVD. In the case of silicon substrate, the presence of native oxide probably prevents the in-plane texture of the layers. In contrast, YSZ films deposited on sapphire show an epitaxial growth. The epitaxial relationships are:

$$
\text { (100) YSZ// (1-102) sapphire and (110) YSZ // (01-12) sapphire. }
$$

2 - YBCO layers were grown on YSZ/Si. At high deposition temperatures, the film consists on well shaped disconnected crystals. In contrast, at lower temperatures the layers are continous but do not exhibit superconducting transition above $77 \mathrm{~K}$. This facts are correlated to : a) the polycrystalline nature of the buffer layer induced by the presence of an amorphous $\mathrm{SiO}_{2}$ interlayer and $b$ ) the formation of a non uniform $\mathrm{BaZrO}_{3}$ interlayer between $\mathrm{YBCO}$ and $\mathrm{YSZ}$.

3 - High quality YBCO c-axis oriented layers were deposited on YSZ/sapphire. The films show in-plane texture which leads to obtain high critical current densities. These values could be probably increased by depositing a buffer layer with a thickness below its epitaxial threshold value, evaluated in $100 \mathrm{~nm}$. In this case, the flat morphology of the buffer layer could induce a $\mathrm{BaZrO}_{3}$ interlayer with an abrupt interphase enhancing, as well, the two-dimensional mechanism of YBCO growth.

\section{Acknowledgements}

The authors are grateful to V.Gomis and L.Balo from ICMAB/CSIC for AC measurements and to X.Alcover and J.Bassas from Serveis cientifico-tecnics (UB) for YBCO texture analysis.

This work has been partially supported by a CICYT program (MAT 0707/93) and a contract Carburos Metàlicos S.A- CSIC.

\section{References}

[1] Mogro-Campero.A, Supercond.Sci.Technol, 3 (1990) 155

[2] Char.K, Fork.D.K, Geballe.T.H, Laderman.S.S, Taber.R.C, Jacowitz.R.D, Bridges.F, Connell.G.A.N and Boyce.J.B, Appl.Phys Lett, 56 (1990) 785

[3] Fenner.D.B, Viano.M, Fork.D.K, Connell.G.A.N, Boyce.J.B, Ponce.F.A and Tramontana.J.C, J.Appl.Phys, 69 (1991) 2176-2182

[4] Wu.X.D, Muenchausen.R.E, Nogar.N.S, Pique.A, Edwards.R, Wilkens.B, Ravi.T.S, wang.D.M.H and Chen.C.Y, Appl.Phys.Lett, 58 (1991) 304-306

[5] Fork.D.K, Fenner.D.B, Barton.R.W, Phillips.J.M, Connell.G.A.N, Boyce.J.B and Geballe.T.H, Appl.Phys.Lett, 57 (1990) 1161-1163

[6] Chocron.S, Tsach.T, Parizh.M, Schieber.M, Deutscher.G, Racah.D, Raizman.A and Rotter.S, Physica C, 185-189 (1991) 2093-93

[7] Schieber.M, Schwartz.M, Koren.G and Aharoni.E, Appl.Phys.Lett, 58 (1991) 301-303

[8] Garcia.G, Llibre.J, Santiso.J, Figueras. A and Aguilo.M, Physica C, 235-240 (1994) $651-652$

[9] Schieber.M and Ariel.Y, Apply Phys Lett, 61 (1992) 970-972

[10] Dorignac.D, Schamm.S, Grigis.Ch, Santiso.J, Garcia.G and Figueras. A, J.Physique, this conference

[11] Hwang.D.M, Ying.Q.Y and Kwok.H.S, Appl.Phys.Lett, 58 (1991) 2429-2431

[12] Ockenfuß.G, Baudenbacher.F, Prusseit-elffroth.W, Hirata.K, Berberich.P and Kinder.H, Physica C, 180 (1991) 30-33

[13] Fork.D.K, Fenner.D.B. Connell.G.A.N, Phillips.J.M and Geballe.T.H, Appl.Phys.Lett, 57 (1990) $1137-1139$ 